\title{
Sylvia Plath, Cláudia Roquette-Pinto, e os limites da escrita: uma poética do autoaniquilamento
}

\author{
Aline Leal Barbosa ${ }^{1}$
}

\begin{abstract}
Resumo: A partir da análise comparativa da poética de Sylvia Plath e de Cláu dia Roquette Pinto, unidas aqui por relação referencial bem como por certo anacronismo, este artigo pretende pensar a construção de uma linguagem que atravessa o tema e a materialidade do corpo, do feminino e da morte. O suicí dio - encarado como questão do limite (Edge, Plath), do corpo, da linguagem, do tempo (contemporâneo) - serve como chave de análise, ora refutada ora apresentada, para se pensar uma escrita obscura, realizada numa espécie de Zona de sombra (Roquette Pinto) entre o dizivel e o indizível, no contato com as margens da vida, que vai recair sobre os extremos da linguagem. Nomes como Van Gogh, Antonin Artaud, Anne Sexton, Ana Cristina César, entre ou tros, são também evocados neste artigo como desagregadores de instituições, como a própria linguagem.
\end{abstract}

Palavras chave: Sylvia Plath; Cláudia Roquette Pinto; corpo; feminino; suicídio; limite.

\section{Introdução}

No conhecido ensaio O que é o con temporâneo (2007), Giorgio Agam ben utiliza a figura do poeta e o po ema "O século" (1923), de Osip Mandel'štam, para refletir a respei to da singular relação que estabele cemos com nosso próprio tempo, afirmando a necessidade de se man ter certa distância com a época em que vivemos, uma vez que aquele que a ela adere totalmente não será capaz de apreendềla. Essa não coincidência - falta de sincronia, segundo o ensaísta - ocorre em termos de uma dissociação e de um anacronismo, que nos permite apreender nosso tempo na forma de um "muito cedo" que é também um "muito tarde", ou seja, um presente que não pode nunca nos alcançar: "O poeta, enquanto contemporâ neo, é essa fratura, é aquilo que im pede o tempo de compor se e, ao mesmo tempo, o sangue que deve suturar a quebra" (AGAMBEN, 2010, p. 61). Sendo sangue que su tura a quebra, o poeta - o' contem porâneo - é aquele que deve man ter fixo o olhar no seuitempo, para nele perceber não as luzes, mas as trevas.

É também a noção de anacronis
1 Doutora em Literatura, Cultu ra e Contempo raneidade pela PUC-RJ. Contato: alinelfbarbo sa@gmail.com. 
mo - e as diferentes conotações que o termo tem adquirido - que Célia Pedrosa (2001), em Considerações anacrônicas: lirismo, subjetividade, resistência, vai utilizar para discor rer a respeito da poesia brasileira contemporânea. No entanto, dife rentèmente do uso que fizeram os críticos que ela analisa, Pedrosa propõe uma estratégia de avaliação e de leitura não pela sua recusa, mas pelo valor que se pode obter desse anacronismo inerente ao li rismo, para usar um termo que se confundiu com a própria lingua gem poética, considerando anacrô nico o próprio ato de se escrever e ler poesia. Para tanto, a crítica toma como exemplo Mário de Andrade, cuja produção literária esteve liga da a uma necessidade de se adaptar às questões de sua época e, ao mes mo tempo, de se libertar de tais cir cunscrições.

Ítalo Moriconi (1998), em Pós modernismo e volta do sublime na poesia brasileira, por sua vez, em bora aponte os progressos do esteti cismo rigoroso contra uma espon taneidade prolixa e "bárbara", pró pria da geração anterior dos poetas marginais, desconfia de certo ana cronismo na restauração de antigos valores literários e propõe a volta de uma linguagem mais solta, do colo quial, do verso livre e, ainda que com certo constrangimento, defen de o retorno de uma imersão da po esia na vida coletiva dos espaços públicos. Moriconi aponta para a existência de um movimento subli mador paralelo ao processo de despolitizacãa das questões de lingua gem, estética, sujeito e corporalida de da produção poética contempo rânea. Segundo o crítico, a poesia contemporânea é onde "todas as conciliações são possíveis e onde a demanda por qualidade coloca se frequentemente no nível do virtuo sismo versejador ou do bom gosto decoroso" (MORICONI, 1998, p. 20). Uma suposta inclinação à valo rização da linguagem teria como alvo ressacralizar a poesia, depois da dessublimação orquestrada pelo Modernismo'e da 'morte do verso decretada pelo Concretismo.

Iumna Maria Simon e Vinícius Dantas (2009), por seu turno, no ensaio Consistência de Corola, apontam para um anacronismo da retradicionalização, no intuito de reagir à poesia culta, séria, intertex tual e hermética. Indicam um dis tanciamento e uma indiferença da poesia em relação à atúalidade, a partir do uso acrítico que se faz do passado, como se os poetas se dis pusessem apenas a alcançar o baú da tradição para dali tirar formas e recombiná las. Sob o rótulo irônico de uma "retradicionalização frívota", defendem uma maior aderência dos poetas à experiência histórica. Por isso exaltam, de forma contun dente, a publicação do poema "Sí tio", de Cláudia Roquette Pinto (2001), em Margem de Manobra. Para aqueles que sustentam que os projetos ideológicos ficáram no pas sado, os críticos apontam a contra dição inerente ao argumento: se o capitalismo venceu, como é que a 
poesia não está lutando contra esse desastre? É evidente a necessidade de Iumna Maria Simon e de Viní cius Dantas de buscarem um ponto de oposição e de se apresentarem como uma espécie de "advogados do diabo" da poesia contemporâ nea, em seu exagero crítico e ponto de vista direcionado.

No poema "O dia inteiro" (2000), que abre o livro Corola, de Cláudia Roquette Pinto, podemos encontrar uma sugestão do senti mento de contemporaneidade, co mo espaço tempo que é de uma só vez tão próximo e distante de nós. Confinada no espaço de um jardim, na busca angustiante por uma ideia, tendo seu esforço intelectual amea çado por "vagalumes tontos contra a teia" e pela esterilidade de um jardim sem "nenhuma floração, nem ao menos um botão incipien te", a poeta empreende um movi mento simultâneo e de aparência contraditória: "Longe daqui, de mim // (mais para dentro)" (ROQUET TE -PINTO, 2000, p. 17).

O deslocamento, aparentemente paradoxal, empreendido ao mesmo tempo para longe e para o interior, propicia uma-visão - síntese da con temporaneidade, na medida em que se afasta para aproximar, para ir "mais para dentro", para mergu lhar em si mesmo, deslocar o foco para longe de onde se está. Porém, confinada no jardim, o fruto deste esforço introspectivo parece levar ao fracasso, pois seus pés acabam por cravar "no rosto desta última flor" (ROQUETTE PINTO, 2000, $p$. 17), na florescência do jardim. Pa rece acontecer aqui um caminho próximo ao que é sugerido por Agamben no ensaio supracitado: o poeta é aquele capaz de escrever mergulhando a pena nas trevas do presente.

\section{Cláudia Roquette Pinto, Sylvia Plath e a redoma de vidro}

Este artigo pretende, ao mesmo tempo, destacar e desconfiar de uma afinidade entre a poesia de Cláudia Roquette Pinto e a de Sylvia Plath, pondo em questão suas seme lhanças e disparidades. No ensaio Consistência de Corola, Iumna Ma ria Simon e Vinícius Dantas (2009) sugerem que Sylvia Plath tenha sido uma influência importante na "dis ciplina da expressão" de Cláudia, apontando, sobrẹtudo, para a visão fora de escala - que denominam miopia - e para uma percepção intensa da realidade. No entanto, seria possível apontar Plath como uma espécie de "paideuma" 2 de Ro quette Pinto? Outros indicativos de que, em algum momento da vida de Cláudia a poeta norte americana se fez presente é o fato de ela ter es crito o artigo "Completamente Plath" no tablóide Verve - que criou nos anos 1980 e no qual este ve à frente durante cinco anos além da tradução do poema "The Munnich Mannequin" (1965) "Os Manequins de Munique" em 1988 para o mesmo veículo e o poema "para sylvia plath", que de dicou à poeta norte americana em seu primeiro livro, Os dias gagos (1991);
2 Paideuma

conceito utilizado por Ezra Pound a partir de Leo

Frobenius - traria a organização do conhecimento para que o próxi mo sujeito ou geração pudesse achar, o mais rapidamente possível, a parte viva dele e gastar o mínimo tempo com itens obsole tos. Em um sentido mais amplo, trata se de uma forte referência a que determinado autor presta reverência em seu texto ou, em sentido contrá rio, deseja elimi ar. 

dou ao teu corpo a fluidez ${ }^{3}$
e a luz
de um suicídio aquoso
invoco, no sono, cabelos
de um teor que não desejo estranhar
imagino teu rosto um aquário
você transborda no vestido árido
peixes olhos
escorregam da tua tez
palavras sem raiz
mergulham na limpidez

Alguns temas importantes da poética de ambas aparecem já neste poema, a saber: o tema da corporei dade, isto é, o corpo como uma pre sença concreta e destituído, ou defi ciente, de arbítrio; o tema da luz/sombra, zonas de determinação e indeterminação; o tema do confi namento/isolamento indicado pelo aquário. E, por último, a imagem do penúltimo verso "palavras sem ra iz", apontando para a linguagem como uma espécie de fuga "desen raizada", para uma "desterritoriali zação", dissolução referencial que gera aquilo que Dantas e Simon de finiram como "equivocidade" ou "anfibolia", em que a incerteza e a obscuridade, provocadas por um dispositivo metafórico ou sintático, prevalecem.

O próprio nome do livro de es treia - Os dias gagos - aponta para uma gagueira que impede o encaixe perfeito das palavras ("o tique que quedou meu dias gagos"). Outro traço identificado em diver sos poemas de Roquette=Pinto é a sensação de deslizamento, como se o poema escorresse, promovesse um movimento decadente. Temos "aquoso", "transbordam", a ima gem "peixes olhos/ escorregam da tua tez" sugerindo olhos que derre tem no rosto, a mórbida figura da poeta morta. O jogo de rimas é mo desto, porém já um indício da ener gia que Cláudia dispensará à sono ridade, por meio de assonâncias, aliterações e rimas internas, nos livros subsequentes, indicado, aqui, por um esquema de cores.

No entanto, é possível que Clau dia Roquette Pinto objetasse contra a comparação ora delineada. $\mathrm{Na}$ entrevista à revista Oroboro (2005), declara considerar o poema "a lei da pólis", também de Os dias gagos, sobre o suicídio de Ana Cris tina César, um rompante de "rup tura bastante adolescente". Talvez Cláudia então quisesse se afastar do culto que formou o cânone sinistro das escritoras suicidas, em que a leitura objetiva é atravessada pela tragédia pessoal, gerando um curio so efeito de leitura, em que o suicí dio aparece como uma presença irremovível, e criatividade e auto destruição são associadas de modo enigmático.

Talvez porque, ainda que possa mos entrever marcas da existência de Cláudia nos versos (a materni dade, a sensação de insegurança da cidade, a chegada à maturidade, a 'referência ao budismo), sua poesia está predominantemente destituída de um sujeito determinado (afora o fato de ser quase sempre uma mu lher que fala no poema), dando poucas dicas e não se confundindo com a autora daquelas, linhas, em um movimento diferente de poetas como Ana Cristina César, Sylvia Plath e Anne Sexton, que derrama ram suas vidas nos poemas em um 
ato confessional de cura e, em al guma medida, de renovação da dor. De fato, Sylvia Plath pertence ao rol de autoras cuja vida se entrelaçou de tal forma a sua obra que os da dos biográficos da poeta constituem uma chave importante para a com preensão de seus poemás. Ana Cecí lia Carvalho, no artigo "A poética do suicídio em Sylvia Plath" indica a' abordagem incontornável dos textos de alguém que se matou em plena produção literária: "a impossível dissociação entre o fantasma da bi ografia da escritora (cujo suicídio funciona como uma presença irre movível) e a construção do texto". Trata se, segundo Ana Cecília, de um curioso efeito de leitura, em que o leitor se vê à procura dos anún cios desse destino trágico em meio às linhas que lê, "campo onde esta riam inscritas as pegadas que, se seguidas, poderiam lhe mostrar o caminho que levou a escritora ao autoextermínio" (CARVALHO, 2003, p. 23).

O sujeito da enunciação dos po emas de Roquette Pinto, no entanto, se coloca recorrentemente como centro do mundo, a partir do qual são referidos os aspectos do real. Este movimento, porém, parece ës tar mais direcionado ao que a poeta associou, no depoimento "Dentro e fora", da antologia Vozes femininas: gênero, mediaçóes e práticas da es crita", com a ideia de refúgio: "essa experiência de interioridade (que, levada ao paroxismo, é a própria claustrofobia) vai se derramar, ne cessariamente, sobre a poesia que faço" (ROQUETTE $\sim$ PINTO; SUS SEKIND et al, 2001, p. 483). Con vém mencionar também que, dife rentemente da poesia marginal feita no Brasil, cujo traço de confessiona lidade é marca determinante de seu processo, as poetas confessionais acima mencionadas não comparti lham do verso espontaneísta e de manifestação antiformalista. Ao contrário, seu processo passa por um gesto de construção formal la boriosa. No prefácio a The complete poems of Anne Sexton (1981), a crítica literária Maxine Kumin dis corre a respeito do processo de fa bricação do poema da poeta inglesa: "There was no more determined reviser than Sexton, who would willingly push a poem through twenty or more drafts"5 (KUMIN; SEXTON, 1981, p. 24).

Outro ponto que merece ser indi cado aqui, sem intenção de com prová lo ou refutá lo, porém mais como comentário de certa forma inescapável ao se analisar duas poe tas cujas temáticas estão - em al guma medida ou supostamente relacionadas ao universo arquetipi camente feminino, é a questão da voz feminina que fala nos poemas. Há aqui duas posições aparente mente divergentes. Paulo Henriques Britto, responsável pelo ensaio so bre Cláudia Roquette Pinto da cole ção Ciranda de Poesia (2010), ape sar de destacar o traço de feminili dade em sua produção poética, con sidera forçado o rótulo de "poesia feminina" para destacar um dado apenas adjacente na poesia de Cláudia. A outra posição, encabeça da por Iumna Simon e Vinícius Dantas, em ensaio supracitado, to ma como ponto de partida o que
${ }^{4}$ Este livro reúne os trabalhos e depoimentos apresentados no seminário "Vozes Femininas: Gênero, Mediações e Práticas da Escri ta", realizado nos dias 23, 24 e 25 de Maio de 2001, na Fundação Casa de Rui Barbosa.

${ }^{5}$ Em tradução livre nossa: "Não havia revisora mais determinada que Sexton, que, sem hesitar, fazia um poema passar por mais de vinte rascunhos." 
Gilda de Mello e Souza define como certa miopia relacionada à posição social da mulher. Historicamente relegada a lugares fechados e se re lacionando com um universo de objetos, a mulher procura sentido no espaço confinado em que á vida se encerra: o quarto e seus perten ces, o jardim e suas flores. A crítica literária desenvolve este pensamen to:

Não será difícil apontar na literatu ra feminina a vocação da minúcia, o apego ao detalhe sensível na trans crição do real, características que, segundo Simone de Beauvoir, deri vam da posição social da mulher. Ligada aos objetos e deles depen dendo, presa ao tempo, em cujo ritmo se sabe fisiologicamente ins crita, a mulher desenvolve um tem peramento concreto e terreno, mo vendo se como coisa num universo de coisas, como fração de tempo num universo temporal. A sua é uma vida refletida, sem valores, sem iniciativa, sem acontecimentos de relevo, e os episódios insignificantes que a compõem, de certo modo só ganham sentido no passado, quando a memória, selecionando o que o presente agrupou sem escolha, fixa dois ou três momentos que se desta cam em primeiro plano. Assim, o universo feminino é um universo de lembrança ou de espera, tüdo vi vendo, não de um sentido imanente mas de um valor atribuído. E como não lhe permitem a paisagem que se desdobra para lá da janela aberta, a mulher procura sentido no espaço confinado em que a vida se encerra: o quarto com os objetos, o jardim com as flores, o passeio curto que se dá até o rio ou a cerca. A visão que constrói é por isso uma visão de mí ope, e no terreno que o olhar baixo abrange, as coisas muito próximas adquirem uma luminosa nitidez de contornos (MELLO e SOUZA apud SIMON; DANTAS, 2009).

No entanto, Simon e Dantas utili zam o conceito de miopia para lan çá lo a outro nível, que consideram mais coerente com uma sociedade em que o gênero não é de tal forma determinante à dinâmica social sendo assim, a poeta incorpora a miopia de forma mais ampla para examinar a estreiteza e a opacidade da vida contemporânea, o enclau suramento resultante da sensação de insegurança e do isolamento dos sujeitos em seus vários tipos de con finamento. Tal visão míope, na ver dade, poderia ser compartilhada tanto pelo homem como pela mu lher e, portanto, não constituiria uma divergência real com a primei ra posição apontada por Paulo Hen riques Britto. A própria poeta já dis correu sobre o tema, ao abrir o também já mencionado artigo "Dentro e fora" indagando: "Existe poesia feminina? A rigor, não. A poesia ou é boa, ou não é. O que me parece inegável é que existem cer tas vivências exclusivamente femi ninas, vivências que necessaria mente se projetam (nem sempre de forma muito óbvia) na poesia que as mulheres fazem" (ROQUETTE PINTO; SUSSEKIND et al, 2001, $p$. 483).

A posição de ícone feminista, por sua vez, foi amplamente divulgada a respeito de Sylvia Plath, por seus poemas que denunciam a violência de uma sociedade patriarcal e tam bém pela voz e temática altamente femininas, por um olhar deforman te de situações banais, cotidianas e domésticas, explicitado, por exem - 
plo, no poema traduzido pela poeta brasileira, "Os Manequins de $\mathrm{Mu}$ nique": "A perfeição é horrível, ela não pode ter filhos. / Fria como o hálito da neve, ela tapa o útero// Onde os teixos inflam como nuvem. / A árvore da vida e a árvore da vida." Seu único románce, $A$ redo ma de vidro (1983), na chave do autoficcional, considerado por al ' guns críticos como um longo poema em prosa (provavelmente com certo exagero, bem como alguns conside ram exagero encarar Corola como um único poema em partes) discor re a respeito de uma menina saindo da adolescência, abordando, entre os temas da loucura e do suicídio, o tema da virgindade e do casamento como tabu e regra social, respecti vamente.

Talvez em razão do enfrentamen to em relação à época em que viveu seja possível apontar uma marcante voz feminina - e feminista - em Sylvia Plath, certamente muito mais forte do que em Cláudia Roquette Pinto. Chamá la feminista, posto ao qual foi alçada por algumas corren tes do movimento postumamente, indica também um teor de anacro nismo referente à especificidade do termo adquirida em diferentes épo cas. Se atualmente mulheres que nunca se professaram feministas são tomadas enquanto tal, há indi cação de um trânsito que ultrapassa a linearidade dos tempos históricos, vivido, porém, como inatualidade e intempestividade. E fato é que Syl via Plath sempre colocou como cen tro de sua poesia a "musa inquie tante", que nunca pretendeu desco lar de sua própria subjetividade.
Outra característica recorrente na poesia da poeta norte americana é a apropriação de mitos clássicos e, de forma menos recorrente, de te mas religiosos e bíblicos para co mentar episódios de sua vida ("Lady Lazarus", "Lesbos", "Medusa", "Reis Magos", entre outros), ade rindo ao caráter trágico desses per sonagens como efeito de dramatici dade ou para invocar sacrifícios corporais. O mesmo não é recor rente na poesia de Cláudia, sendo mais comum a assimilação de par tes da flor e do universo vegetal pa ra comentar não a própria vida, mas a dinâmica da escrita de um poema, seja na busca de imagens para tentar defini lo, o que resultou em diversos metapoemas, sobretudo em "Corola", seja na intenção de retratar algum objeto das artes plásticas, atitude mais comum em "Saxífraga". Outra técnica que apa rece em Roquette Pinto é a das cita ções, ou empréstimos, como ela as definiu em Margem de Manobra, elencando os trechos de outros au tores utilizados por ela nos poemas.

\section{Análise de "Edge" (Limite), de Sylvia Plath, e "Suspenso na re de", de Claudia Roquette Pinto}

\section{Edge}

The woman is perfected.

Her dead

Body wears the smile of accomplishment, The illusion of a Greek necessity

Flows in the scrolls of her toga, Her bare 
Feet seem to be saying:

We have come so far, it is over.

Each dead child coiled, a white serpent, One at each little

Pitcher of millk, now empty.

She has folded

Them back into her body as petals

Of a rose close when the garden.

Stiffens and odors bleed

From the sweet, deep throats of the night flower.

The moon has nothing to be sad about, staring from her hood of bone.

She is used to this sort of thing. Her blacks crackle and drag.

\section{Limite}

A mulher está perfeita.

Morto,

Seu corpo mostra um sorriso de

A ilusão de uma necessidade grega

[satisfação,

Flui pelas dobras de sua toga,

Nus, seus pés

Parecem nos dizer:

Fomos tãolonge, é o fim.

Căda criança morta, uma serpente

Em voltade cada

[branca,

Vasilha de leite, agora vazia.

Ela abraçou

Todas em seu seio como pétalas

De uma rosa que se fecha quando o

Se espessa e odores sangram

[jardim

Da garganta profunda e doce de uma flor [noturna.

A lua não tem nada que estar trisfe,

Espiando tudo de seu capuz de osso.

Ela já está acostumada a isso.

Seu lado negro avança e draga.

\section{Suspenso na rede}

Suspenso na rede do sono na tarde

em ser, ainda, tarde, ou ver $\sim$ se noite [indecisa o corpo, em seu torpor, não acredita sequer na hipótese de um corpo (em morte, em vida, e o quedizer do encontro).

É certo que lá fora algo acontece, insetos voam, pessoas (seus ruídos) sobem, descem, pensam que isso é tudo:

a terra embaixo acima o céu

e nuvens.

Às vezzes um clarão

de raro em raro

o Entoquant necessita a folha

para estender sua bandeira tola

no ar mesquinho

(e antes que qualquer lagarta a alcance).

De resto é este sono que se alonga

até a sombra,

na tarde em avalanche.

Os dois poemas acima foram se lecionados por indicar alguns pon tos de contato temáticos e formais entre as duas poetas. No que diz respeito à forma do poema, pode mos verificar o amplo uso de en jambements em "Edge", recurso também muito utilizado por Cláu dia Roquette Pinto, embora com cada vez menos recorrência, preva lecendo o corte semântico nos poe mas mais recentes. Também se constata uma economia, um enxu gamento, espécie de contenção no poema de Plath, que foi provavel mente o último que escreveu em vida, que o diferencia de sua pro dução anterior, caracterizada por certa confessionalidade irrefreada. Este, no entanto, é um traço corri queiro da poesia de Cláudia Ro quette Pinto, geralmente bastante sintética. 
Em relação ao jogo de rimas, po demos ver que ambas as poetas pre zam pela rima interna, que abunda nos poemas, ainda que, de fato, existam outros exemplos, sobretudo da poeta brasileira, em que esta técnica é ainda mais fortemente empregada, denotandó certo preci osismo. Fica claro, pelo esquema de cores, que, na tradução de "Edge", as rimas internas ficaram em se gundo plano, prevalecendo os en jambements e o estilo seco do origi nal.

$\mathrm{Na}$ questão temática, pode mos ressaltar pontos de encontro que permeiam de forma mais abrangente a poética de Sylvia Plath e Cláudia Roquette Pinto. O primei ro é certa obscuridade semântica: na poeta brasileira, ocasionada so bretudo por uma construção sintá tica rarefeita, aquilo que denomi namos anteriormente como anfibo lia, com diversas inversões entre o sujeito e o objeto ("Suspenso na re de do sono na tarde indecisa / em ser, ainda, tarde, ou ver se noite / o corpo, em seu torpor, não acredi ta"), e, na poeta norte americana, pelo efeito gerado pelas incontáveis metáforas e-símiles, ocasionando ambiguidade e indeterminação.

As duas técnicas empregadas fundamentam um itinerário incerto para o leitor, uma atmosfera de ir realidade sobre a qual ele vai flutu ar até $\mathrm{o}$ fim do poema $\mathrm{e}^{-}$somente um esforço de interpretação será capaz de fazê lo atribuir sentido aos versos - no caso de Plath, muito por meio de uma associação com os dados biográficos da autora que margeiam o poema, e, no caso de
Cláudia, ao destrinchar as funções sintáticas e reordená las na frase. Esta escrita obscura, realizada nu ma espécie de "zona de sombra" entre o dizível e o indizível, está associada também a uma experiên cia dos limites, ao contato com as margens da vida, que vai recair so bre os extremos da linguagem. Co mo apontaram Simon e Dantas em ensaio supracitado, as duas poetas empregam a mesma visão fora de escala de uma percepção intensa, traduzida em imagens, "capaz de deformar os objetos em cena e au mentar fisicamente os sentimentos" (SIMON; DANTAS, 2009).

Entregar se à morte será con templar a totalidade da existência, seu alcance global? Daí que a morte apareça como miragem e dispositi vo poético, como lugar privilegiado para se pensar as tensões de ativi dade limítrofe, derrubar os limites ainda que temporariamente, de modo que Roquette Pinto e, de for ma mais próxima e determinante Plath, mantiveram na como foco de luz solar, insuportável e incontor nável, temida e desejada. Além dis so, à morte tenderam poeticamente, apostando nessa linguagem, e no que ela tem de transgressão e perda, como motor para a atividade literá ria.

A corporeidade é outro tema que surge de forma recorrente na obra das duas poetas. Eliane Robert Mo raes (2001), em O corpo impossí vel, contextualiza o gesto estético destrutivo como resposta à crise do humanismo ocidental, entre o final do século XIX e a Segunda Guerra Mundial. A sensação de dispersão e 
instabilidade provocada pela vida moderna terá no corpo o alvo prin cipal a ser atacado, sua integridade física feita em pedaços. Assim, ao artista moderno restava capturar os fragmentos desta época em seus instantes de presente: "A arte mo derna respondeu à trama do caos através de formas fraturadas, estru turas parodísticas, justaposições inesperadas, registros de fluxos de consciência e da atmosfera da am biguidade e ironia trágica que ca racterizam tantas obras do período" (MORAES, 2001, p. 57).

Em Margem de Manobra, por exemplo, dos 17 poemas da primei ra seção, homônima ao livro, em nove deles a palavra "corpo" apare ce, e, em sua maioria, ele constitui o eixo temático do poema. São eles: "Queda", "E ela soube que tinha sido atravessada", "Tudo a perder", "Opaco", "Sob o toque da luz do dia", "A escada de Jacó", "Medita ção", "Rol", “... entre pernas, entre braços". E, ainda que nos outros o corpo não apareça de forma explí cita, é sugerido ou aludido por me tonímias. Em um primeiro momen to associado à sensualidade femini na, frequentemente metaforizado por uma flor, em Corola, a princi pal ideia que ele parece indicar é a de uma prisão, como aparece em "Não a garganta" e em "Dentro do pescoço". No entanto, enquanto que em Claudia o corpo é um objeto ín tegro e luminoso nos primeiros li vros, passa a ser ameaçado a partir de Zona de sombra e é radicalmente perfurado e estraçalhado em Már gem de manobra.

Na poética de Sylvia Plath, o dila - ceramento do corpo é mais ou me nos uma constante. Geralmente, na poeta norte americana, o corpo surge representado por suas partes como experiência concreta e confi nadora, como um peso que se car . rega separado de sua essência. Por exemplo, em Ariel (1965): "Me ar rasta pelos ares / coxas, pelos; / escamas de meus calcanhares. // Godiva / Branca, me descasco / Mãos mortas, asperezas mortas". Em "Lady Lazarus": "O nariz, as covas dos olhos, a dentadura toda? / O hálito amargo / Desaparece num dia. // Em muito breve a car ne / Que a caverna carcomeu vai estar / Em casa, em mim.". Em "A coragem de calar": "A coragem da boca fechada, apesar da artilharia! / A linha rósea e quieta, um verme, exposto ao sol." Outra presença corpórea marcante na poesia de Sylvia Plath é a de bebês e de crian ças; em "Lesbos": "O bebê sorri, lesma obesa, / Dos losangos relu zentes do linóleo laranja. ! Dá para comề lo. É um menino"; em "Um segredo": "Bébê ilegítimo - / Aque la cabeça imensa e azul!". Em geral, nos poemas de Plath o corpo é uma presença latente em direção à mor te, ao seu extermínio, o suicídio em cena: "Morrer / É uma arte, como tudo o mais. / Nisso sou excepcio nal" ("Lesbos [2]"). A morte é en carada como um ato voluntário, uma atração, um desejo de vida.

Nas duas poetas, o corpo fre quentemente apparece como um ou tro, alteridade, um duṕlo que é um encontro com o primeiro: "o corpo, em seu torpor, não acredita/ sequer na hipótese de um corpo/, (em mor te, em vida, e / o que dizer do en - 
contro)". Ainda em Roquette $\sim$ Pinto, no poema em prosa "E ela soube que tinha sido atravessada": "E a culminância para onde ela (em ca da um dos seus corpos) convergia, ao abrir se em pétalas, tornava in separáveis a queda aniquiládora do seu próprio corpo, entregue ao cor po que estava ali, é o vislumbre, si multaneamente doce, do outro cor " po, ausente." E em "A escada de Ja có": "Sim, o corpo era o caminho / mas outra coisa nela se movera / e agora erguia seu rodamoinho / pe los canais, / enquanto o corpo, ou tro, / tiritava, transitava sem piloto / do nulo à súbita doçura, / ao ti gre, ao terremoto, / à menina que ela tinha sido."

Outra chave em que se pode ana lisar o duplo em C.R.P. é a partir das referências gramaticais, empre gadas sobretudo nos metapoemas, duplicando a referência à escrita, como em "O dia inteiro": "que em gerúndio vara madrugadas", "mí nimo onde o superlativo esbarra"; e em "O torneadọ": "O torneado há bil das palavras / o dissonante vão das consoantes". Na poeta norte americana, este duplo se traduz a partir de uma autoconsciência, um olhar aguçado sobre a própria pës soa do poema. Outra leitura sobre o duplo em Sylvia Plath pode ser feitá a partir do eu do poema em relação ao eu original da poeta.

No entanto, esse movimento pa rece tratar se menos de uma tarefa identificadora do que de uma ope ração de deslizamentó entre os sig nificantes, de modo a indicar um devir ininterrupto que propõe a instabilidade das identidades e dos nomes, outrora talvez um dos últi mos redutos de segurança e repou so. Se a linguagem é um dos alicer ces do real, estrutura fundamental do mundo humano, a poesia, por sua vez, vai tratar de transgredir os limites desta organização, embara lhar os signos, de modo a evocar o movimento de continuidade e des fragmentação na tendência ao ab soluto, tendência de morte. Mas a recusa de um nome próprio resulta ao mesmo tempo na proliferação de nomes, no exercício vertiginoso de resvalar e fixar.

\section{Considerações finais}

Sylvia Plath parece estar dentre aqueles artistas detentores de de terminada virtude extraordinária, que vivem na mesma medida ator mentados por certa visão insupor tável, certa lucidez doentia, visioná rios que indicam uma saída ao mesmo tempo que acusam uma li mitação.' Van Gogh, Nietzsche, Ar taud, Marquês de Sade; Maura Lo pes Cançado, Ana Cristina César, Virgínia Woolf: aqueles para quem a consciência não levou a uma frie za das paixões, a um prazer tempe rado, mas, no limite do seu contor no, experimentaram o extremo do possível, ém toda a sua sordidez e angústia, de modo tal que seu pra zer violento foi considerado, por vezes, patológico. Antonin Artaud diz a propósito de Van Gogh:

Não, Van Gogh não éra louco, mas seus quadros eram misturas incen diárias, bombas atômicas, cujo ân gulo 
gulo de visão comparado ao de to das as pinturas que faziam furor na época teria sido capaz de transfor mar gravemente o conformismo larval da burguesia do Segundo Im pério e dos esbirros de Thiers, de Gambetta, de Felix Faure, como os de Napoleão III. Porque a pintura de Vàn Gogh não afaca um certo con formismo dos costumes, mas as próprias instituições. E até a nature za exterior, com seus climas, suas marés e suas tormentas equinociais não podem mais, depois da passa gem de Van Gogh pela Terra, con servar a mesma gravitação. Com maior motivo, no plano social as instituições se desagregam, e a me dicina parece um cadáver inutiliza do, decomposto, que declara Van Gogh louco (ARTAUD, s/d, p.9).

Van Gogh desestabiliza a ordem do real, porque ele pode mais, mos tra um real ainda mais sensível, um real mais que real, e tomá lo como louco apenas denuncia a própria doença da sociedade. Artaud come ça assim Van Gogh, o suicidado da sociedade: "Pode se proclamar a boa saúde mental de Van Gogh, que durante toda a sua vida somente assou uma das mãos e, além disso, não passou de cortar a orelha es querda" (ARTAUD, s/d, p.9).

No ensaio "A mutilação sacrifici al e a orelha cortada de Van Gogh", Georges Bataille relata a história de Gaston. F., um desenha dor de bordados que decepou o in dicador esquerdo com os próprios dentes. Atraído pelos raios do sol, fixou nele o seu olhar e acreditou receber o comando de secção. Pare ce que o automutilador havia lido uma biografia de Van Gogh em que aprendera que o pintor, em um ataque de loucura, havia metido a faca na própria orelha, embora, como aponta Bataille (2007, p. 95), "quando uma decisão intervém com a violência necessária para se cortar um dedo, escapa por completo às sugestões literárias que tenham po dido antecedê la; e a ordem que os dentes tão repentinamente tiveram que acatar deve surgir como uma necessidade que ninguém consegui ria resistir".

Fixar o sol como pulsão suicida, outrora considerado por alienistas como sinal incurável de loucura. Em 1889, no asilo de alienados de Saint Rémy, Van Gogh ergue os olhos para o "sol em toda a sua gló ria", expressão que ele emprega em uma carta ao irmão, época em que sua obsessão solar chega a um pon to culminante (BATAILLE, 2007, $p$. 96). Em julho de 1890, depois de sair de Saint $\sim$ Rémy, Van Gogh co mete suicídio.

O artista como figura de sensibi lidade apurada e sentimentos inten sos, figura do caos e da angústia, do sofrimento e da solidão. Não recu samos este retrato, nele reconhece mos algo do fazer artístico em sua perda de referenciais, em sua con dição abismal, em sua renúncia aos contratos, e enfim em sua relação íntima com a loucura, embora esta seja uma relação construída histori camente, sistematizada em fins do século XIX. Não foram poucos aqueles que escolheram renunciar à arte face ao sofrimento desta aber tura extrema, ou mesmó a renúncia mais definitiva à vida. Escrever co mo um empreendimento de intensa vulnerabilidade, um projeto de ris co, diríamos mesmo um/flerte com 
a loucura, em seu projeto de con frontar o corpo da lei e da letra.

Existirá uma fenda e aquele que for capaz de vislumbrá la chegará mais próximo da verdade, corren do, porém, o risco de cegar se? É preciso, contudo, escapar às arma dilhas que contrapõem a cegueira à visão, a loucura à sanidade, e pen sar sobretudo em evitar sistemas de determinação e exclusão, ao ampli ar as zonas de cruzamento. Habitar momentaneamente os clarões aber tos por essas autoras e refletir a partir dessa experiência e do resí duo que sobrevém em sua esteira: terá sido essa nossa estratégia de aproximação.

\section{Sylvia Plath, Cláudia Roquette Pinto and the limits of writing: a poetics of self $\sim$ annihilation}

Abstract: From the comparative analysis of the poetics of Sylvia Plath and Claudia Roquette Pinto, united here by reference relation as well as by anachronism, this article intends to think the con struction of a language that crosses the subject and the materiality of the body, the feminine and death. Suicide - regarded as a matter of limit (Edge, Plath), body, language, time (contemporary) - serves as an analysis key, sometimes refuted, other times acknowledged, to think of this obscure "writing, performed in a kind of "shadow zone" between the speakable and the unspeakable, in contact with the margins of life, which will fall on the extremes of language. Names such as Van Gogh, Antonin Artaud, Anne Sexton, Ana Cristina César, among others, are also evoked in this article as disintegrators of institutions, such as language itself.

Keywords: Sylvia Plath; Cláudia Roquette-Pinto; body; female; suicide; limit.

\section{Referências}

AGAMBEN, Giorgio. O que é o contemporâneo? e outros ensaios. Chapecó: Argos Editora, 2009.

ARTAUD, A. Van Gogh: o suicidado pela sociedade. 2 ed. Rio de Janeiro: Achiamé, s. d.

BATAILLE, Georges. O ânus solar (e outros textos). Trad. Aníbal Fernandes. Lisboa: Assírio e Alvim, 2007.

BRITTO, Paulo Henriques. Claudia Roquette Pinto. Coleção Ciranda da Poesia. Rio de Janeiro: EdUERJ, 2010.

CARVALHO, Ana Cecília. A poética do suicídio em Sylvia Plath. In: Em tese. Belo Ho rizonte, vol 3, p.21 29, dez. 1999.

KUMIN, Maxine. How it was. In: SEXTON, Anne. The Complete Poems of Anne Sex ton. Massachusetts: Houghton Mifflin Company Boston, 1981. 
MELLO, Heitor Ferraz. Poesia presente: Cláudia Roquette-Pinto. Disponível em: $<$ http://www.claudiaroquettepinto.com.br/>.

MORAES, Eliane Robert. O corpo impossivel: a decomposição da figura humana: de Lautréamont a Bataille. São Paulo: Iluminuras, 2002.

MORICONI, Ítalo. Pós modernismo e volta do sublime na poesia brasileira. In: PE DROSA, C. et al. Poesia hoje. Rio de Janeiro: EdUFF, 1998, p. 11 26.

PEDROSA, Célia. Considerações anacrônicas: lirismo, subjetividade, resistência. In: CAMARGO, Maria Lúcia de Barros; PEDROSA, Célia (orgs). Poesia e contempora neidade: leituras do presente. Chapecó: Argos, 2001. p. 7 23.

PLATH, Sylvia. A Redoma de Vidro. Rio de Janeiro: Editora Globo S.A., 1991. . Ariel. Campinas: Verus Editora, 2007.

ROQUETTE PINTO, Cláudia. Os Dias Gagos. Rio de Janeiro: Edição da autora, 1991. . Saxifraga. Rio de Janeiro: Salamandra, 1993.

. Zona de Sombra. Rio de Janeiro: 7 Letras, 1997.

. Corola. São Paulo: Ateliê Editorial, 2000.

. Margem de Manobra. Rio de Janeiro: Aeroplano, 2005.

. Dentro e Fora. In: SUSSEKIND (org.) Vozes Femininas, gêneros, media çóes e práticas de escrita.

SIMON, Iumna; DANTAS, Vinícius. Consistência de Córola. In: Novos Estudos CE BRAP85. São Paulo, 2009. Disponível em:

$<$ http://www.scielo.br/scielo.php?pid=S0101

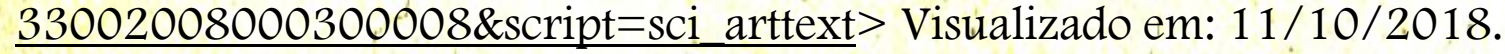

Recebido em: 28/11/2018

Aprovado em: 29/03/2019 